\title{
Formation of Acidic Phopholipids in Rabbit Lung during Perinatal Development
}

\author{
MIKKO HALLMAN'(4:1) AND LOUIS GLUCK \\ Division of Perinatal Medicine. Department of Pediatrics, School of Medicine, University of California. San Diego, \\ La Jolla. California. USA
}

\begin{abstract}
Summary
Phospholipids were measured in the lamellar bodies and alveolar lavage of perinatal rabbits. Between 28 and 31 fetal days, phosphatidylinositol (PI) increased, and phosphatidylserine decreased. Small amounts of phosphatidylglycerol (PG) appeared at term. After birth, PG markedly increased and PI concomitantly decreased. PG increased prematurely after removal from the uterus of fetuses 29 days gestation or more. Fatty acid analysis of PG and PI revealed the presence of 62 to $63 \%$, and 58 to $59 \%$, of saturated species, respectively. As measured in total lung homogenate, PI increased between 28 and 31 fetal days, and PG increased between term and the first neonatal day.

Glycerol incorporation into PG increased at birth, according to the measurement of lung slices. myo-Inositol incorporation into PI increased in the fetus parallel to accumulation of surfactant.

The development of the following enzyme activities was studied in subcellular fractions derived from lung homogenates: phosphatidate cytidyltransferase, cytidine $\mathbf{5}^{\boldsymbol{\prime}}$-diphosphate (CDP)-diglyceride:inositol transferase, glycerophosphate phosphatidyltransferase, and phosphatidylglycerophosphatase. As measured in the microsomal fraction, all the activities increased between 27 and 30 fetal days. Shortly after birth, phosphatidate cytidyltransferase and glycerophosphate phosphatidyltransferase increased further, whereas the two other enzyme activities decreased somewhat. Cytidine $5^{\prime}$-diphosphate diglyceride:inositol transferase increased after the newborn period. There were only small developmental changes in $K_{m}$ 's. In contrast to microsomes, the mitochondrial activities mainly decreased during development. Phosphatidylglycerophosphatase was the only activity that was present in significant amounts in lamellar bodies.

It is proposed that the developmental changes in the acidic surfactant phospholipids are due to changes in the biosynthesis rates in type II cell microsomes. This may be controlled both by changes in the enzyme activities (phosphatidate cytidyltransferase, cytidine $5^{\prime}$-diphosphate diglyceride:inositol transferase, and glycerophosphate phosphatidyltransferase) and by changes in substrate concentrations (myo-inositol and $s n$-glycerol-3-P).
\end{abstract}

\section{Speculation}

Besides surfactant lecithin, phosphatidylglycerol is critical to alveolar stability and its absence may precipitate respiratory distress syndrome in the newborn. Surfactant phosphatidylglycerol and phosphatidylinositol serve as indices of fetal lung maturity or help to specify diagnosis of respiratory distress in the neonate. Because several hormones seem to regulate individual surfactant phospholipids, the measurement of these components (lung profile) could be a way to analyze consequences of hormonal or nutritional balance and eventually correct it if necessary.

Biochemical research on surfactant has been focused on the biosynthesis and regulation of the major surfactant compound, lecithin (phosphatidylcholine (PC)] and its main component, disaturated PC (47). These studies were greatly stimulated by the introduction of the lecithin/sphingomyelin $(\mathrm{L} / \mathrm{S})$ ratio as a prenatal index of fetal lung maturity (14). Thus, the widely accepted concept that a lack of surfactant causes the respiratory distress syndrome (RDS) $(2,14)$ is based largely upon studies on PC. Knowledge of the other surfactant components is far less complete.

Surfactant PG recently was shown to be an indicator of lung maturity: it is lacking in RDS but present in healthy newborns and in diseases other than RDS (18). The other phospholipids of lung effluent are present in RDS, although in reduced (PC) or increased (sphingomyelin, phosphatidylserine, and phosphatidylethanolamine) quantities $(18,35)$. PG may also be useful in prenatal amniotic fluid analyses because its presence indicates lung maturity despite high-risk pregnancy or when blood or meconium contamination of the amniotic fluid hampers the maturity tests (22). This epidemiologic evidence, supported by surface activity measurements, has led to the postulate that PG is a surfactant component essential in stabilizing the alveoli, particularly during acute stresses. Absence of PG at birth could precipitate RDS with trensitional, or, exceptionally, even with an L/S ratio of two or more.

In adult rodents, PG is located preferentially in the surfactant fractions, namely on the extracellular lining of the airways and in intracellular lamellar bodies of type II alveolar cells (19). According to some authors, lamellar bodies contain high specific activities of PG synthesizing enzymes $(4,26,41)$. However, quantitatively, by far most of the biosynthetic activity has been found in microsomal fractions and in mitochondria $(19,41)$.

Phosphatidate cytidyltransferase (EC 2.7.7.41) (I), glycerophosphate phosphatidyltransferase (EC 2.7.8.5) (II), and phosphatidylglycerophosphatase (EC 3.1.3.27) (III) catalyze the biosynthesis of PG as follows (46).

(I) Phosphatidic acid + cytidine triphosphate $\rightarrow$ cytidine 5'-diphosphate (CDP)-diglyceride + $\mathrm{PP}_{\mathrm{i}}$

(II) Sn-Glycerol-3-phosphate + CDP-diglyceride $\rightarrow$ phosphatidylglycerolphosphate + cytidine monophosphate

(III) Phosphatidylglycerolphosphate $\rightarrow \mathrm{PG}+\mathrm{P}_{\mathrm{i}}$

In addition to PG, biosynthesis of phosphatidylinositol (PI) requires $\mathrm{CDP}$-diglyceride in a reaction catalyzed by CDP-diglyceride:inositol transferase (EC 2.7.8.11) (IV):

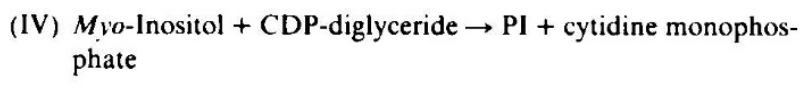

In the present communication, we have studied the formation of phospholipids in the lung during perinatal development. The above-mentioned enzyme activities were studied particularly in a fraction derived from crude microsomes. We further document the successive appearance of surfactant components and propose a mechanism for stepwise development of surfactant PI and PG. 
MATERIALS AND METHODS

New Zealand albino rabbits were used. The time of conception was known to within $2 \mathrm{hr}$. The day of conception was considered day zero. Under light ether anesthesia, 20 to $30 \mathrm{ml}$ of air was injected IV into the does. The fetuses were removed quickly from the abdominal cavity, and their necks and abdominal aortae were cut before the onset of breathing. Only when specifically indicated, were the preterm fetuses allowed to breathe room air. The number of animals in each litter was 5 to 15. For isolation of the subcellular organelles, the number of animals was as follows: for 28-day-old or younger fetuses, the whole litter: from 29-day-old fetuses to 8day-old rabbits, 3 to 8 animals.

Reference phospholipids, except for phosphatidyldimethylethanolamine (Sigma Chemical Co., St. Louis, MO) and CDP. diglycerides (Serdary Research Laboratories, London, Ontario, Canada) were products of Supelco. CDP-diglycerides were purified by lipid extraction at $\mathrm{pH} 8$, followed by acidification of the water phase and reextraction at $\mathrm{pH} \mathrm{2,} \mathrm{according} \mathrm{to} \mathrm{Eichberg} \mathrm{and}$ Hauser (12). The purified CDP-diglyceride thus obtained migrated as a single spot in thin-layer chromatography. Phosphatidylglycerolphosphate was derived from diphosphatidylglycerol using Bacillus cereus phospholipase C (EC 3.1.4.3) (Sigma Chemical Co.) (10) and subsequently isolated on two-dimensional thin-layer chromatography. The identity of the lipid was verified by analyzing the chemical composition $(39,40)$; the molar ratio of phosphorus:glycerol:fatty acid was $1.00: 96: 1.02$, i.e., close to the theoretical, $1: 1: 1$. bis(Glycerol) phosphate was prepared by deacylation of phosphatidylglycerolphosphatase as described by Dawson (9). Phospholipase D (cabbage) (EC 3.1.4.4) and $s n$-glycerol-3-P were purchased from Calbiochem. Phospholipase $\mathrm{A}_{2}$ (Naja Naja venom) (EC 3.1.1.4) was the product of Sigma Chemical Co.

The radioactive isotopes were purchased from New England Nuclear (Boston, MA) except for $\left[1,3,{ }^{3} \mathrm{H}\right]$ glycerol, which was supplied by Amersham/Searle. Radioactive phosphatidylglycerolphosphate was synthesized in the presence of $s n-\left[U-{ }^{14} \mathrm{C}\right]$ glycerol3-P, CDP-diglyceride, and mercuric chloride using the membrane fraction derived from Escherichia coli, essentially according to Chang and Kennedy (7). The radioactive lipid was isolated using two-dimensional thin-layer chromatography. To further confirm the identity of the radioactive lipid, it was deacylated according to Dawson (9). The resulting compound was isolated on a thin-layer chromatogram as described previously (19); $94 \%$ of the radioactivity was associated with bis(glycerol)phosphate standard.

\section{PHOSPHOLIPID ANALYSIS}

The total lipids were extracted according to Bligh and Dyer (5) using chloroform:methanol $(2: 1, v / v)$. Phospholipids were separated by two-dimensional thin-layer chromatography on laboratory-made (I5) silica gel $\mathrm{H}$ (E. Merck) plates as described previously (30), and the individual lipids were quantified on the basis of phosphorus contents (27). Disaturated PC was isolated according to Mason et al. (33).

The fatty acid components of the phospholipids were analyzed by gas-liquid chromatography (15). The acidic phospholipids on thin-layer plates were identified by spraying with water or methanol. The individual phospholipids were eluted using a solution containing chloroform:methanol: $\mathrm{H}_{2} \mathrm{O}: 58 \% \mathrm{NH}_{4} \mathrm{OH}$ (3:6:0.5:0.5 $\mathrm{v} / \mathrm{v})$. The eluate was neutralized using $0.1 \mathrm{M} \mathrm{Na}$ citrate $(\mathrm{pH} \mathrm{2.0)}$ and the lipids were recovered by extraction according to Bligh and Dyer (5). One-half of the specimen was treated with phospholipase $A_{2}$ followed by fatty acid analysis of lysophospholipids (1-position) and free fatty acids (2-position). The other one-half was analyzed without phospholipase treatment. The individual fatty acids were expressed as percentage of total fatty acids. The results were acceptable only when the mean fatty acid composition of lysophospholipids and free fatty acid fractions were similar to the total fatty acid composition (difference in individual fatty acids less than $\pm 4 \%$ ).

\section{ISOLATION OF LUNG FRACTIONS}

Before isolation, the animals were exsanguinated through the abdominal aorta. The lungs were chilled in ice cold $0.27 \mathrm{M}$ sucrose:0.01 M Tris-HCl:0.1 mM EDTA ( $\mathrm{pH}$ 7.4). All subsequent steps took place at 0 to $4^{\circ} \mathrm{C}$. After removal of the large bronchi, the tissue was weighed and minced with scissors. The tissue was homogenized with three complete strokes of a motor-driven Teflon pestle homogenizer (clearance 0.15 to $0.23 \mathrm{~mm}$; Arthur Thomas Co.). The final homogenate contained $3 \mathrm{ml}$ of $0.27 \mathrm{M}$ sucrose:Tris: EDTA per $1 \mathrm{~g}$ of fetal lung or $4 \mathrm{ml}$ of $0.27 \mathrm{M}$ sucrose:Tris:EDTA per $1 \mathrm{~g}$ of postnatal lung. After centrifugation at $900 \times \mathrm{g}$ for 10 min, the resulting supernatant was poured through double-thickness of cheesecloth. The supernatant, called cell-free homogenate, was thereafter spun at $8000 \times g$ for 10 min to obtain lamellar body-mitochondrial pellet and a new supernatant containing microsomes. The lamellar body-mitochondrial pellet was resuspended in $0.27 \mathrm{M}$ sucrose:Tris:EDTA and layered on the top of the discontinuous density gradient containing $4 \mathrm{ml}$ of $1.3 \mathrm{M}$ sucrose:Tris:EDTA $4 \mathrm{ml}$ of $0.55 \mathrm{M}$ sucrose:Tris:EDTA and $1 \mathrm{ml}$ of $0.45 \mathrm{M}$ sucrose:Tris:EDTA. The gradients were centrifuged at $85,000 \mathrm{~g}_{\mathrm{av}}$ for $60 \mathrm{~min}$ using SW-27 rotor (Beckman Instruments). The resulting pellet was resuspended in $0.27 \mathrm{M}$ sucrose:Tris:EDTA and washed once by sedimentation at $10,000 \times g$ for $10 \mathrm{~min}$. The sediment was the mitochondrial fraction. Lamellar body fraction was collected as the layer containing $0.45 \mathrm{M}$ sucrose:Tris:EDTA, diluted with excess of $0.27 \mathrm{M}$ sucrose:Tris:EDTA, and sedimented at $10,000 \times g$ for $10 \mathrm{~min}$.

For isolation of microsomes, the $8000 \times g$ supernatant was further spun at $10,000 \times g$ for $10 \mathrm{~min}$. The resulting supernatant was layered over a discontinuous density gradient containing $4 \mathrm{ml}$ of $1.3 \mathrm{M}$ sucrose:Tris:EDTA and of $4 \mathrm{ml}$ of $0.55 \mathrm{M}$ sucrose:Tris: EDTA. After centrifugation at $100,000 \mathrm{~g}_{\mathrm{av}}$ for $2 \mathrm{hr}$ in SW 27 rotor, the material between 1.3 and $0.55 \mathrm{M}$ sucrose:Tris:EDTA was recovered, diluted to $0.27 \mathrm{M}$ sucrose:Tris:EDTA, and sedimented at $230,000 \mathrm{~g}_{\mathrm{av}}$ for one $\mathrm{hr}$ using a Ti 50 rotor.

Endobronchial lavage was performed through a catheter inserted into the trachea. First, the lungs were gently inflateddeflated with air. This was followed by four lavagings each time with 1.5 to $75 \mathrm{ml}$ of $0.15 \mathrm{M} \mathrm{NaCl}\left(20^{\circ} \mathrm{C}\right)$, depending on the size of the animals. This procedure removes more than $70 \%$ of the phospholipids that can be collected during 10 washings. The combined lavage fluid was centrifuged for $10 \mathrm{~min}$ at $200 \times \mathrm{g}$ to remove any cells. When indicated, the surfactant phospholipids of the lavage fluid were further purified using density gradient centrifugation (21).

\section{ASSAYS OF PHOSPHOLIPID BIOSYNTHESIS}

Slice Experiments. The lungs were rapidly removed and chilled in ice-cold Krebs-Ringer phosphate buffer. Most of the bronchial tissue was removed. Lung slices weighing from 45 to $65 \mathrm{mg}$ were prepared using a Stadie-Riggs slicer (Arthur Thomas Co., Philadelphia, PA). The slices were incubated in Krebs-Ringer bicarbonate containing $6.9 \mathrm{mM}$ glucose and either $0.15 \mathrm{mM}\left[1,3,-{ }^{3} \mathrm{H}\right]$ glycerol, myo $\left[2-{ }^{3} \mathrm{H}\right]$ Inositol $(0.15 \mathrm{mM})$ or $0.15 \mathrm{mM}$ sn-glycerol-3$\mathbf{P}$ (specific activity, $46 \mu \mathrm{Ci} / \mu$ mole). Incubation took place for 30 min at $37^{\circ} \mathrm{C}$ with shaking in flat-bottomed flasks, each containing one slice and $0.7 \mathrm{ml}$ of incubation medium, under a slow stream of $95 \% \mathrm{O}_{2}: 5 \% \mathrm{CO}_{2}$. After the incubation, the lipids were extracted, and total phospholipid content and radioactivity associated with PG and PI were measured.

Measurements of Enzymatic Activities. The assays were done in conical flasks at $37^{\circ} \mathrm{C}$ with shaking, volume, 0.07 to $0.10 \mathrm{ml}$. Reactions were stopped by the addition of $0.6 \mathrm{ml}$ methanol, 1.2 $\mathrm{ml}$ of chloroform, and $0.5 \mathrm{ml}$ of $100 \mathrm{mM} \mathrm{Na}$-citrate $(\mathrm{pH} 2.0$ ) containing $10 \mathrm{mM}$ of the unlabeled precursor. The lipid phase was removed, and the upper phase was reextracted with $1 \mathrm{ml}$ of theoretical lower phase (chloroform:methanol:water, 86:14:1 v/ v). The resulting lower phase was combined with the previous 
lower phase and extracted with $0.2 \mathrm{ml}$ of $100 \mathrm{mM} \mathrm{Na}$ citrate $(\mathrm{pH}$ 2.0 ). Thereafter, the radioactivity associated with the lower phase was measured. The enzyme activities were optimized with respect to $\mathrm{pH}$, except when specifically indicated.

Phosphatidate cytidyltransferase activity was assayed by measuring the rate of cytidine 5 -triphosphate (CTP) incorporation into CDP:diglyceride. The final reaction mixture contained 100 $\mathrm{mM}$ Tris:Maleate ( $\mathrm{pH} 7.0$ ), $0.55 \mathrm{mM}$ phosphatidic acid (prepared by sonication in the presence of Cutscum), $0.2 \mu \mathrm{g} / \mathrm{ml}$ Cutscum, $3.0 \mathrm{mM}\left[5-{ }^{3} \mathrm{H}\right] \mathrm{CTP}$ (specific activity, $17.1 \mu \mathrm{Ci} / \mu \mathrm{mol}$ ), $40 \mathrm{mM}$ $\mathrm{MgCl}_{2}$, and 0.8 to $1.5 \mathrm{mg} / \mathrm{ml}$ protein. The rate of incorporation was linear for $10 \mathrm{~min}$. In the results shown, the incubation time was 5 to $10 \mathrm{~min}$. The reaction was started by addition of the enzyme preparation followed by addition of $\mathrm{MgCl}_{2}$. Omission of $\mathrm{MgCl}_{2}$ inhibited the activity by $60 \%$. More than $90 \%$ of the radioactive lipid formed was recovered with CDP:diglyceride after two-dimensional thin-layer chromatography. Therefore, in routine assays the radioactivity was measured in the reextracted lipid phase. Each preparation was also assayed in the absence of phosphatidic acid and detergent.

CDP-Diglyceride:inositol transferase activity was assayed by measuring the rate of incorporation of myo-inositol into $\mathrm{Pl}$ in the presence of CDP-diglyceride. The reaction mixture in routine assays contained $0.3 \mathrm{mM} \mathrm{CDP}$-diglyceride, $150 \mathrm{mM}$ Tris-Cl (both $\mathrm{pH} 7.5$ and $\mathrm{pH} 8.5$ ), $5.6 \mathrm{mM}$ reduced glutathione, $1.5 \mathrm{mM}$ myo$\left(2-{ }^{3} \mathrm{H}\right)$-inositol (specific activity, 8.8 to $\left.9.6 \mu \mathrm{Ci} / \mu \mathrm{mol}\right), 5 \mathrm{mM}$ $\mathrm{MnCl}_{2}$, and 0.2 to $0.4 \mathrm{mg} / \mathrm{ml}$ protein. CDP-Diglyceride was first added in chloroform, which was then evaporated. Freshly prepared $\mathrm{MnCl}_{2}$ was added last, immediately before incubation, followed by brief sonication in a water bath (model 8845-3; ColePalmer Instrument $\mathrm{Co}$, Chicago, IL) at $0^{\circ} \mathrm{C}$. The rate of incorporation was linear for $20 \mathrm{~min}$. The incubation time was $10 \mathrm{~min}$. More than $95 \%$ of the radioactive lipid formed during the incubation coincided with authentic PI in two-dimensional thin-layer chromatography. Therefore, in routine assays, the radioactivity was measured in the reextracted lipid phase.

Freshly prepared microsomes showed little if any incorporation of inositol into PI in the absence of CDP-diglyceride. Addition of detergents failed to increase the activity. Manganese $(4$ to $7 \mathrm{mM}$ $\mathrm{MnCl}_{2}$ ) was required for maximum activity. Further addition of $\mathrm{Mg}^{++}$did not improve the incorporation rate.

Glycerophosphate phosphatidyltransferase was assayed by measuring the rate of incorporation of $s n-\left[U-{ }^{14} \mathrm{C}\right]$ glycerol-3-P into phosphatidylglycerolphosphate and PG in the presence of CDPdiglyceride (18). The reaction mixture contained $0.2 \mathrm{mM}$ CDPdiglyceride, $80 \mathrm{mM}$ Tris- $\mathrm{Cl}(\mathrm{pH} 7.4), 6 \mathrm{mM}$ reduced glutathione, $0.45 \mathrm{mM} s n$-glycerol-3-P $(15.3 \mu \mathrm{Ci} / \mu$ mole $)$, and 0.8 to $1.5 \mathrm{mg} / \mathrm{ml}$ protein. The incubation time was $10 \mathrm{~min}$. In the presence of repurified CDP-diglyceride, 90 to $97 \%$ of the radioactive lipid was associated with $P G$ and phosphatidylglycerolphosphate. Therefore, in routine assays the radioactivity was measured in total lipid extract. Only when specifically indicated were the phospholipids isolated using two-dimensional thin-layer chromatography and the radioactivity associated with PG, phosphatidylglycerolphosphate, diphosphatidylglycerol, and bis(monoacylglycerol) phosphate measured as described previously (18).

Phosphatidylglycerophosphatase activity was measured by incorporation of phosphatidyl $\left[{ }^{14} \mathrm{C}\right.$ ]glycerolphosphate into PG essentially as described by Johnston et al. (26). The incubation mixture contained $0.1 \mathrm{mM}$ phosphatidylglycerolphosphate (specific activity, $1.2 \mu \mathrm{Ci} / \mu$ mole), $0.18 \%$ Triton $\mathrm{X}-100,90 \mathrm{mM}$ Tris-maleate ( $\mathrm{pH}$ $6.8)$, protein $(0.08$ to $0.10 \mathrm{mg} / \mathrm{ml})$. After the incubation and extraction of lipids, phospholipids were isolated using two-dimensional thin-layer chromatography, and the radioactivity associated with PG and phosphatidylglycerolphosphate was measured. The recovery of radioactivity in PG and phosphatidylglycerolphosphate spots was 79 to $86 \%$. This somewhat low figure is largely explained by the fact that the loss of phosphatidylglycerolphosphate during the lipid extraction was 9 to $13 \%$. However, the recovery of PG was always close to $100 \%$.

Other Methods. The activities of succinate dehydrogenase (EC
1.3.99.1), and rotenone-insensitive NADPH:cytochrome $c$ reductase (EC 1.6.2.4) were measured according to Sottocasa (43). Protein was quantified according to Lowry et al. (32). Phospholipid radioactivity was measured according to Webb and Mettrick (48). External standardization was used to correct the quenching. The results are expressed as means \pm S.E. Statistical significance was calculated using the $t$ test (Student distribution).

\section{RESULTS}

Microsomes, mitochondria, and lamellar bodies were examined for contamination using mitochondrial (succinate dehydrogenase) and microsomal (NADPH:cytochrome $c$ reductase) marker enzymes. Table 1 shows the distribution of the marker enzymes in mitochondria and in microsomes. On the basis of succinate dehydrogenase activities, there was less than $5 \%$ mitochondrial contamination in microsomal fraction, regardless of the source of the organelles. There was somewhat more microsomal contamination in mitochondrial fractions. However, due to low fetal activity of NADPH:cytochrome $c$ reductase, microsomal contamination could not be evaluated in most fetuses. Lamellar bodies were not contaminated by mitochondria (succinate dehydrogenase activity in lamellar bodies less than $5 \%$ of that in mitochondria), and there were small amounts of microsomal contamination (NADPH:cytochrome $c$ reductase activity in lamellar bodies 5.4 to $9.5 \%$ of that in microsomes).

Table 2 illustrates total phospholipid/protein ratios in lamellar bodies and in alveolar lavage from different age groups. An increase in phospholipid content was noted between the 28 th and 30 th fetal days. Phospholipid content in lamellar bodies exceeded those in alveolar lavage regardless of the age. We further purified alveolar lavage by density gradient centrifugation. The surfactant thus obtained had at least as high a phospholipid protein ratio as lamellar bodies. On the other hand, the phopholipid composition of crude alveolar lavage and its fraction isolated by density gradient were similar (data not shown). These measurements suggest that a remarkable part of proteins recovered during alveolar lavage come from sources other than lamellar bodies.

\section{PHOSPHOLIPID COMPOSITION}

The composition of individual phospholipids in the lung during perinatal development are shown in Table 3 . The results resemble those from Gluck et al. (16). However, in the present study the acidic phospholipids, PG, bis(monoacylglycerol)phosphate, and diphosphatidylglycerol (cardiolipin) have been analyzed in detail. The percentage amounts of PC and PG increased during development. PI increased between days 26 and 27 and 30 and 31 in the fetus. The contents of phosphatidylethanolamine and diphosphatidylglycerol decreased somewhat, whereas changes in sphingomyelin and phosphatidylserine were more variable.

Table 4 presents phospholipid composition in lamellar bodies and alveolar lavage from 28- and 30-day-old fetuses. Phospholipids $2 \mathrm{hr}$ after delivery by cesarean section are presented, too. Sphingomyelin, phosphatidylethanolamine, and phosphatidylserine were significantly higher, but PC and PI were significantly lower in alveolar lavage than in lamellar bodies. In 30-day-old animals $2 \mathrm{hr}$ after delivery by cesarean section, the composition of alveolar lavage had become similar to that in lamellar bodies. However, in 28-day-old animals, even after air-breathing, the phospholipid composition as compared between alveolar lavage and lamellar bodies remained different. In 30-day-old animals, PG increased at birth, whereas in 28-day-old animals it remained absent.

In 28-day-old fetuses, the total phospholipids recovered by alveolar lavage $(0.8 \pm 0.3 \mathrm{nmoles} / \mathrm{mg}$ residual lung protein) were less and remained smaller after $2 \mathrm{hr}$ of air breathing $(1.5 \pm 0.6$ $\mathrm{nmoles} / \mathrm{mg}$ residual lung protein) than in 30 -day-old ones ( $3.3 \pm$ $0.5 \mathrm{nmoles} / \mathrm{mg}$ protein; $7.3 \pm 1.2 \mathrm{nmoles} / \mathrm{mg}$ protein after $2 \mathrm{hr}$ of air-breathing).

The development of the acidic surfactant phospholipids in lamellar bodies is shown in Figure 1. Diphosphatidylglycerol was 
Table 1. Distribution of succinate dehydrogenase and NADPH:cytochrome c reductase between mitochondria and microsomes as an index of microsomal and mitochondrial contamination ${ }^{1}$

\begin{tabular}{|c|c|c|c|c|c|c|c|}
\hline \multirow[b]{2}{*}{ Age } & \multicolumn{3}{|c|}{$\begin{array}{c}\text { Succinate dehydrogenase } \\
\text { (nmoles } \times \mathrm{min}^{-1} \times \mathrm{mg}^{-1} \text { protein) }\end{array}$} & \multirow{2}{*}{$\begin{array}{c}\text { Mitochondrial } \\
\text { contamination } \\
\text { in microsomes }\end{array}$} & \multicolumn{2}{|c|}{$\begin{array}{c}\text { NADPH:cytochrome } c \\
\text { reductase } \\
\left(\text { nmoles } \times \text { min }{ }^{\prime} \times \mathrm{mg} \text { ' protein) }\right.\end{array}$} & \multirow{2}{*}{$\begin{array}{c}\begin{array}{c}\text { Microsomal } \\
\text { contamination } \\
\text { in mitochondria }\end{array} \\
(\%)\end{array}$} \\
\hline & $N^{2}$ & Mitochondria & Microsomes & & Mitochondria & Microsomes & \\
\hline \multicolumn{8}{|l|}{ Fetus } \\
\hline 24-27 days & 4 & 119.2 & 3.8 & $3.2(1.3-5.4)^{3}$ & n.m. ${ }^{4}$ & n.m. & \\
\hline 28-31 days & 3 & 110.0 & 2.7 & $2.5(0.0-4.2)$ & n.m. & n.m. & \\
\hline \multicolumn{8}{|l|}{ Newborn } \\
\hline $0-2$ days & 3 & 127.5 & 2.9 & $2.0(1.2-3.2)$ & 13.5 & 121.4 & $10.9(5.9-14.2)$ \\
\hline 4-8 days & 3 & 158.2 & 3.0 & $1.7(1.0-2.3)$ & 13.2 & 127.0 & $10.3(9.4-11.0)$ \\
\hline Adult & 3 & 139 & 3.2 & $3.8(2.8-5.1)$ & 6.7 & 80.1 & $8.0(6.1-10.3)$ \\
\hline
\end{tabular}

'The contamination was calculated using the following equations:

$$
\left\{\begin{array}{l}
\text { succinate dehydrogenase } M_{1} / x=\text { succinate dehydrogenase } M_{*} /(1-y) \\
\text { NADPH:cytochrome } c \text { reductase } M_{1} /(1-x)=\text { NADPH:cytochrome } c \text { reductase } M_{*} / y
\end{array}\right.
$$

where $x=$ the portion of the mitochondrial fraction representing pure mitochondria, and $y=$ the portion of the microsomal fraction representing pure microsomes.

${ }^{2} N$, number of assays.

${ }^{3}$ Numbers in parentheses, range.

${ }^{4}$ n.m., not measured.

\begin{tabular}{|c|c|c|c|}
\hline Age & $\begin{array}{c}\text { Lamellar bodies } \\
\text { (nmoles phospholipid/mg protein) }\end{array}$ & $\begin{array}{c}\text { Alveolar lavage } \\
\text { (nmoles phospholipid/mg protein) }\end{array}$ & $\begin{array}{l}\text { Purified surfactant } \\
\text { (nmoles phospholipid/mg protein) }\end{array}$ \\
\hline \multicolumn{4}{|l|}{ Fetus } \\
\hline 28 days & $4413 \pm 306^{2}(4)^{3}$ & $886 \pm 83(4)$ & n.m. ${ }^{4}$ \\
\hline 29-30 days & $7770 \pm 377$ & $1896 \pm 82(6)$ & $10202(2)$ \\
\hline \multicolumn{4}{|l|}{ Newborn } \\
\hline $0-2$ days & $7811 \pm 402$ & $2834 \pm 190(11)$ & $11030(3)$ \\
\hline Adult & $8100 \pm 395$ & $3417 \pm 239(7)$ & n.m. \\
\hline
\end{tabular}

Table 2. Phospholipid:protein ratio in lamellar bodies, alveolar lavage, and purified surfactant recovered from rabbit lung

' Purified surfactant was derived from alveolar lavage as previously described (21).

${ }^{2}$ Mean \pm S.E.

${ }^{3}$ Numbers in parentheses, number of assays.

${ }^{4}$ n.m., not measured.

never detected, and bis(monoacylglycerol)phosphate was always less than $1.0 \%$ of the total phospholipids (data not shown). The changes in the other acidic phospholipids are shown. Toward term, the concentration of phosphatidylserine decreased, and PI increased. The second change took place after birth; PG increased from the low fetal values, and PI decreased. Throughout development, there were only small changes in the sum of the three phospholipids.

The ratio of PG in homogenate (Table 3 ) and lamellar bodies (Fig. 1) was studied. In the fetus, the ratio was at least one, however, at birth is decreased sharply below one. This suggests that the neonatal increase in lung PG was due mainly to an increase in surfactant PG.

Table 5 shows the fatty acid components of surfactant PG and PI. Fatty acids associated with 1- and 2-position were measured separately. More than $40 \%$ of the total fatty acids associated with the 2-position of PG were saturated. The corresponding percentage for PI was somewhat lower. Palmitate was always the major fatty acid constituting more than $75 \%$ of total saturated fatty acids. As shown in Table 5, the phospholipids were isolated from animals of different ages. Our analysis failed to detect any age-dependent changes in fatty acids. However, the data are insufficient to permit critical evaluation of developmental trends in fatty acid composition.

\section{LUNG SLICE EXPERIMENTS}

Phospholipid incorporation in lung slices was studied using the following isotopes: $\left[1,3-{ }^{3} \mathrm{H}\right] \mathrm{glycerol}, m y o\left[2-{ }^{3} \mathrm{H}\right]$ inositol and $s n[U$ ${ }^{14} \mathrm{C}$ ]glycerol-3-P. The apparent rates of $s n$-glycerol-3-P incorporation into $P G$ ranged between 0.1 and 0.5 pmoles $P G \times \mathrm{min}^{-1}$ $\times$ nmoles $^{-1}$ phospholipid-P. It increased significantly at birth. However, glycerol incorporation into PG was markedly higher than that of $s n$-glycerol-3-P. Therefore, the penetration of $s n$ glycerol-3-P into the cell may be slow and seriously limit the incorporation. The apparent rates of glycerol incorporation into PG are shown in Figure 2 . The rate slightly decreased $(P<0.025)$ between the 26th and 28th fetal days. At birth, the activity doubled. Thereafter, only small changes in PG incorporation were detected. After phospholipase D treatment, 79 to $86 \%$ of the radioactivity associated with $P G$ was released from the lipici, indicating that most of the glycerol was incorporated in the headgroup glycerol.

The apparent rate of myo-inositol incorporation into PI almost doubled between the 26 th and 30 th days. Thereafter, activity 
revealed little change. (Fig. 2). All of the radioactivity was released from the lipid during phospholipase D treatment. Neither PG nor PC contained any radioactivity.

\section{THE ACTIVITIES OF PHOSPHOLIPID SYNTHESIZING ENZYMES}

Phosphatidate Cytidyltransferase. Addition of phosphatidic acid to the reaction mixture stimulated $\left[5-{ }^{3} \mathrm{H}\right] \mathrm{CTP}$ incorporation into CDP-diglyceride. Mere dispersion of phosphatidic acid by sonication stimulated the rate of incorporation less (1.2- to 1.8-fold higher rate than without phosphatidic acid) than when both phosphatidic acid and a nonionic detergent, Cutscum, were dispersed together (4.8- to 9.7 -fold higher rate than without phosphatidic acid and Cutscum).

Figure 3 shows phosphatidate cytidyltransferase activities as measured in microsomal and mitochondrial fractions as a function of age. Microsomal activity increased markedly during the perinatal period, whereas after the first neonatal day, there were only small changes. Mitochondrial phosphatidate cytidyltransferase revealed little change during development.

Table 6 shows the apparent $\mathrm{K}_{\mathrm{m}}$ 's for CTP as measured in mitochondrial and microsomal fractions from different age groups. The preparations studied revealed only small differences in the apparent $\mathrm{K}_{\mathrm{m}}$.

CDP-Diglyceride:Inositol Transferase. Figure 4 shows CDP-diglyceride:inositol transferase activity in microsomal fraction as a function of age. The assays were done both in physiological $\mathrm{pH}$ (7.4) and in optimal $\mathrm{pH}(8.5)$. Inasmuch as the fatty acid structure of the natural precursor is unknown, both egg lecithin derivative of CDP-diglyceride and dicaproyl CDP-diglyceride were used in the assay. The egg lecithin derivative of CDP-diglyceride gave a

Table 3. Phospholipid composition in the lung during perinatal development

\begin{tabular}{|c|c|c|c|c|c|c|c|c|c|c|}
\hline \multirow[b]{2}{*}{ Age } & \multirow[b]{2}{*}{$N^{1}$} & \multicolumn{9}{|c|}{ \% phospholipid phosphorus } \\
\hline & & PC & $\begin{array}{l}\text { Sphingo- } \\
\text { myelin }\end{array}$ & $\begin{array}{l}\text { Phosphati- } \\
\text { dylethanol- } \\
\text { amine }\end{array}$ & $\begin{array}{l}\text { Phosphati- } \\
\text { dylserine }\end{array}$ & PI & $\mathrm{PG}$ & $\begin{array}{l}\text { bis-(Mono- } \\
\text { acylglycerol) } \\
\text { - phosphate }\end{array}$ & $\begin{array}{l}\text { Diphospha- } \\
\text { tidylglycerol }\end{array}$ & Recovery $^{2}$ \\
\hline \multicolumn{11}{|l|}{ Fetus } \\
\hline $24-25$ days & 6 & $41.9 \pm 1.3^{3}$ & $7.2 \pm 0.4$ & $35.6 \pm 1.8$ & $9.4 \pm 0.5$ & $3.6 \pm 0.1$ & $0.8 \pm 0.3$ & n.m. ${ }^{4}$ & $1.5 \pm 0.2$ & $90.4 \pm 3.9$ \\
\hline $26-27$ days & 6 & $46.3 \pm 1.8$ & $8.1 \pm 0.6$ & $26.4 \pm 0.8$ & $13.6 \pm 1.4$ & $3.1 \pm 0.3$ & $0.8 \pm 0.2$ & n.m. & $1.7 \pm 0.2$ & $89.9 \pm 4.4$ \\
\hline 28 days & 5 & $45.9 \pm 0.9$ & $9.5 \pm 0.3$ & $25.7 \pm 1.0$ & $12.5 \pm 1.0$ & $4.6 \pm 0.1$ & $0.5 \pm 0.2$ & n.m. & $1.3 \pm 0.3$ & $91.7 \pm 3.7$ \\
\hline 29 days & 4 & $51.1 \pm 2.3$ & $8.9 \pm 0.5$ & $22.4 \pm 1.3$ & $10.6 \pm 0.3$ & $4.8 \pm 0.2$ & $0.6 \pm 0.1$ & $0.4 \pm 0.3$ & $1.2 \pm 0.1$ & $93.4 \pm 1.0$ \\
\hline $30-31$ days & 7 & $51.7 \pm 1.9$ & $9.4 \pm 0.5$ & $20.5 \pm 0.7$ & $10.4 \pm 0.9$ & $5.5 \pm 0.2$ & $0.9 \pm 0.1$ & $0.6 \pm 0.4$ & $1.0 \pm 0.4$ & $90.0 \pm 5.7$ \\
\hline \multicolumn{11}{|l|}{ Newborn } \\
\hline I days & 4 & $53.0 \pm 2.6$ & $8.3 \pm 0.2$ & $20.9 \pm 0.5$ & $10.0 \pm 0.4$ & $4.5 \pm 0.3$ & $1.7 \pm 0.2$ & $0.8 \pm 0.0$ & $0.8 \pm 0.2$ & $87.3 \pm 4.0$ \\
\hline $2-4$ days & 6 & $53.1 \pm 2.5$ & $9.2 \pm 0.4$ & $19.7 \pm 0.9$ & $9.4 \pm 1.0$ & $4.0 \pm 0.2$ & $2.5 \pm 0.2$ & $1.0 \pm 0.5$ & $1.1 \pm 0.1$ & $94.2 \pm 4.4$ \\
\hline Adult & 5 & $54.0 \pm 1.9$ & $11.2 \pm 0.3$ & $17.1 \pm 1.1$ & $9.1 \pm 0.6$ & $3.6 \pm 0.1$ & $3.0 \pm 0.3$ & $1.0 \pm 0.1$ & $1.0 \pm 0.2$ & $90.9 \pm 2.9$ \\
\hline
\end{tabular}

${ }^{1} N$, number of individual assays performed in total lung homogenate.

${ }^{2}$ The sum of individual phospholipid-P in percentage of total chloroform soluble phosphorus.

${ }^{3}$ Mean \pm S.E.

${ }^{4}$ n.m., not measured.

Table 4. Phospholipids in alveolar wash and in lamellar bodies from 28-and 30-day-old fetuses and newborns delivered by cesearean section

\begin{tabular}{|c|c|c|c|c|c|c|c|c|c|c|}
\hline \multirow[b]{2}{*}{ Age } & \multirow[b]{2}{*}{$\mathbf{N}^{\prime}$} & \multirow[b]{2}{*}{$\begin{array}{c}\text { Disaturated } \\
\text { PC } \\
\text { (\% of total } \\
\text { PC) }\end{array}$} & \multicolumn{7}{|c|}{$\%$ of phospholipid-P } & \multirow{2}{*}{$\begin{array}{c}\text { Recov- } \\
\text { ery (\% of } \\
\mathrm{CHCl}_{3-} \\
\text { soluble } \\
\text { phospho- } \\
\text { rus) }\end{array}$} \\
\hline & & & PC & $\begin{array}{l}\text { Sphingo- } \\
\text { myelin }\end{array}$ & $\begin{array}{l}\text { Phosphati- } \\
\text { dylethanol- } \\
\text { amine }\end{array}$ & $\begin{array}{l}\text { Phosphati- } \\
\text { dylserine }\end{array}$ & PI & PG & $\begin{array}{l}\text { bis- } \\
\text { (Mono- } \\
\text { acylgly- } \\
\text { cerol) } \\
\text { phosphate }\end{array}$ & \\
\hline \multicolumn{11}{|l|}{28 days old } \\
\hline Lamellar bodies & 4 & $53.6 \pm 2.0^{2}$ & $70.5 \pm 2.2$ & $7.1 \pm 0.5$ & $8.4 \pm 0.5$ & $4.4 \pm 0.5$ & $9.0 \pm 0.7$ & $0.2 \pm 0.3$ & $0.4 \pm 0.4$ & $92 \pm 4$ \\
\hline \multicolumn{11}{|c|}{$\begin{array}{l}\text { Two hr after delivery by } \\
\text { cesearean section: }\end{array}$} \\
\hline Lamellar bodies & 2 & 55.0 & 70.1 & 6.6 & 8.9 & 4.8 & 9.3 & 0.2 & 0.1 & 94 \\
\hline Alveolar wash & 11 & $48.8 \pm 2.7$ & $61.2 \pm 1.9$ & $14.5 \pm 1.1$ & $10.0 \pm 0.9$ & $6.3 \pm 0.7$ & $7.0 \pm 0.4$ & $0.0 \pm 0.1$ & $1.0 \pm 0.0$ & $91 \pm 6$ \\
\hline \multicolumn{11}{|l|}{30 days old } \\
\hline Lamellar bodies & 6 & $60.0 \pm 3.6$ & $77.5 \pm 2.9$ & $1.0 \pm 0.7$ & $5.8 \pm 0.3$ & $1.7 \pm 0.3$ & $13.2 \pm 1.1$ & $0.6 \pm 0.4$ & $0.2 \pm 0.1$ & $98 \pm 4$ \\
\hline $\begin{array}{l}\text { Alveolar wash } \\
\text { Two hr after ces } \\
\text { section: }\end{array}$ & 7 & $51.2 \pm 0.9$ & $63.5 \pm 3.4$ & $12.0 \pm 0.7$ & $8.0 \pm 0.2$ & $6.9 \pm 0.8$ & $8.0 \pm 0.5$ & $0.4 \pm 0.5$ & $1.2 \pm 0.6$ & $93 \pm 2$ \\
\hline Lamellar bodies & 2 & 57.2 & 76.8 & 1.8 & 5.3 & 1.9 & 12.0 & 2.9 & 0.3 & 94 \\
\hline Alveolar wash & 6 & $56.9 \pm 2.7$ & $73.0 \pm 3.1$ & $3.0 \pm 0.2$ & $6.4 \pm 0.3$ & $2.6 \pm 0.1$ & $11.8 \pm 1.0$ & $2.2 \pm 1.0$ & $1.0 \pm 0.0$ & $92 \pm 4$ \\
\hline
\end{tabular}

${ }^{1} N$, Number of assays.

${ }^{2}$ Mean \pm S.E. 


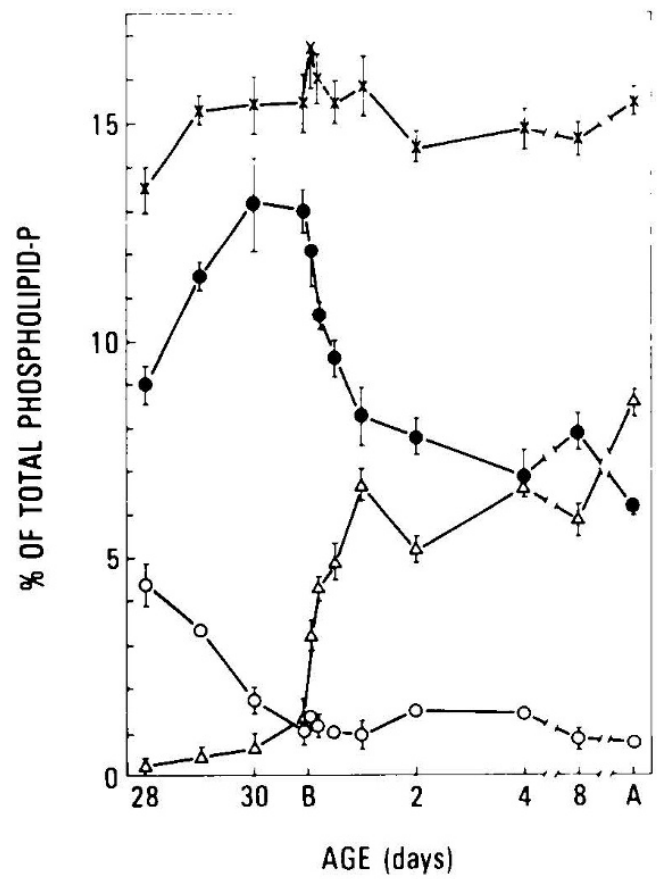

Fig. 1. The contents of the acidic phospholipids in lamellar bodies during the perinatal development. Phosphatidylglycerol $(\Delta)$, phosphatidylinositol (O), phosphatidylserine $(O)$, and the sum of the three acidic phospholipids $(\times)$, $B$, birth; $A$, adult.

Table 5. The percentage of fatty acid composition of surfactant $P G$ and $P I^{1}$

\begin{tabular}{|c|c|c|c|c|}
\hline & \multicolumn{2}{|c|}{ PG } & \multicolumn{2}{|c|}{ PI } \\
\hline & 1-position & 2-position & 1-position & 2-position \\
\hline \multicolumn{5}{|c|}{ Lamellar bodies } \\
\hline & \multicolumn{2}{|c|}{5 assays } & \multicolumn{2}{|c|}{6 assays } \\
\hline 14:0 & $0.7 \pm 0.6^{2}$ & $2.0 \pm 0.2$ & $1.5 \pm 0.2$ & $1.8 \pm 0.2$ \\
\hline $16: 0$ & $73.8 \pm 4.9$ & $36.1 \pm 2.2$ & $62.5 \pm 2.9$ & $27.7 \pm 1.1$ \\
\hline $16: 1$ & $0.6 \pm 0.7$ & $10.7 \pm 0.8$ & $0.9 \pm 0.0$ & $7.4 \pm 1.1$ \\
\hline $18: 0$ & $8.2 \pm 1.5$ & $3.2 \pm 0.7$ & $14.2 \pm 1.2$ & $7.9 \pm 0.6$ \\
\hline $18: 1$ & $12.4 \pm 0.6$ & $40.7 \pm 3.0$ & $6.9 \pm 0.4$ & $30.5 \pm 1.1$ \\
\hline $18: 2$ & $0.8 \pm 0.1$ & $6.1 \pm 0.5$ & $7.0 \pm 0.0$ & $16.6 \pm 1.2$ \\
\hline Others & $3.5 \pm 1.9$ & $1.2 \pm 0.7$ & $7.0 \pm 1.0$ & $8.1 \pm 0.1$ \\
\hline Saturated & $82.7 \pm 4.2$ & $41.3 \pm 2.5$ & $78.2 \pm 3.4$ & $37.4 \pm 1.6$ \\
\hline
\end{tabular}

Alveolar wash

\begin{tabular}{lrrrr} 
& \multicolumn{2}{c}{5 assays } & \multicolumn{2}{c}{5 assays } \\
$14: 0$ & $2.9 \pm 0.2$ & $2.9 \pm 0.6$ & $2.0 \pm 0.3$ & $2.0 \pm 0.4$ \\
$16: 0$ & $73.8 \pm 3.1$ & $36.2 \pm 1.1$ & $64.8 \pm 2.9$ & $31.7 \pm 1.9$ \\
$16: 1$ & $2.2 \pm 0.9$ & $8.3 \pm 0.9$ & $1.3 \pm 0.1$ & $8.0 \pm 0.7$ \\
$18: 0$ & $7.0 \pm 0.8$ & $4.0 \pm 0.2$ & $12.4 \pm 2.9$ & $5.3 \pm 0.5$ \\
18.1 & $11.4 \pm 0.5$ & $41.1 \pm 2.7$ & $13.7 \pm 1.0$ & $29.8 \pm 1.6$ \\
$18: 2$ & $1.0 \pm 0.9$ & $5.7 \pm 0.4$ & $0.8 \pm 0.2$ & $17.0 \pm 1.1$ \\
Others & $1.7 \pm 0.8$ & $1.8 \pm 0.3$ & $5.0 \pm 0.7$ & $6.2 \pm 0.8$ \\
Saturated & $83.7 \pm 3.6$ & $43.1 \pm 1.5$ & $79.2 \pm 2.9$ & $39.0 \pm 2.3$
\end{tabular}

' PG's were obtained from 2-hr to 8-day-old animals, PI's were obtained from 30-day-old fetuses to 8-day-old newborns.

${ }^{2}$ Mean \pm S.E.

lower activity than dicaproyl CDP-diglyceride. The developmental pattern was fairly similar regardless of the assay conditions used; the activity increased during the late fetal period and transiently decreased during the first neonatal days. CDP-diglyceride: inositol transferase activity in mitochondria was $20 \%$ or less than that in microsomes and thus could be due mainly to microsomal contamination (data not shown).
Table 6 shows the apparent $\mathrm{K}_{\mathrm{m}}$ 's for myo-inositol and CDPdiglyceride as measured in microsomes from different age groups. Only small changes were detected. In three instances, we measured $\mathrm{K}_{m}$ using dialyzed microsomal membranes. This did not have an effect on $\mathrm{K}_{\mathrm{m}}$, suggesting that no endogeneous myo-inositol was present.

Glycerophosphate Phosphatidyltransferase. Figure 5 shows the development of the rate of $s n$-glycerol-3-P incorporation into phospholipids in lung microsomes, mitochondria, and cell-free homogenates. In cell-free homogenate, glycerophosphate phos-

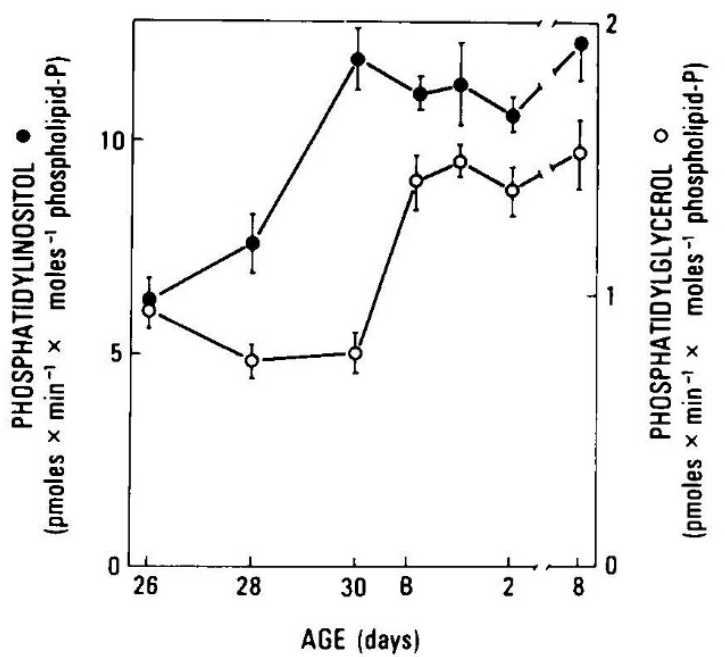

Fig. 2. The apparent rates of incorporation of $0.15 \mathrm{mM} m y o-\left[2-{ }^{3} \mathrm{H}\right]$ inositol (specific activity, $51 \mathrm{mCi} / \mathrm{mmole}$ ) into phosphatidylinositol (๑) and $0.15 \mathrm{mM}\left[1,3-{ }^{3} \mathrm{H}\right]$ glycerol (specific activity, $308 \mathrm{mCi} / \mathrm{mmole}$ ) into phosphatidylglycerol $(\mathrm{O})$ of lung slices obtained from perinatal rabbits. Incubation in Krebs-Ringer bicarbonate was done in flat-bottomed tubes under 95\% $\mathrm{O}_{2}: 5 \% \mathrm{CO}$, for $30 \mathrm{~min}$. For other details, see "Materials and Methods." The results are expressed as the mean \pm S.E. of 4 to 8 measurements run in duplicate. $B$, birth.

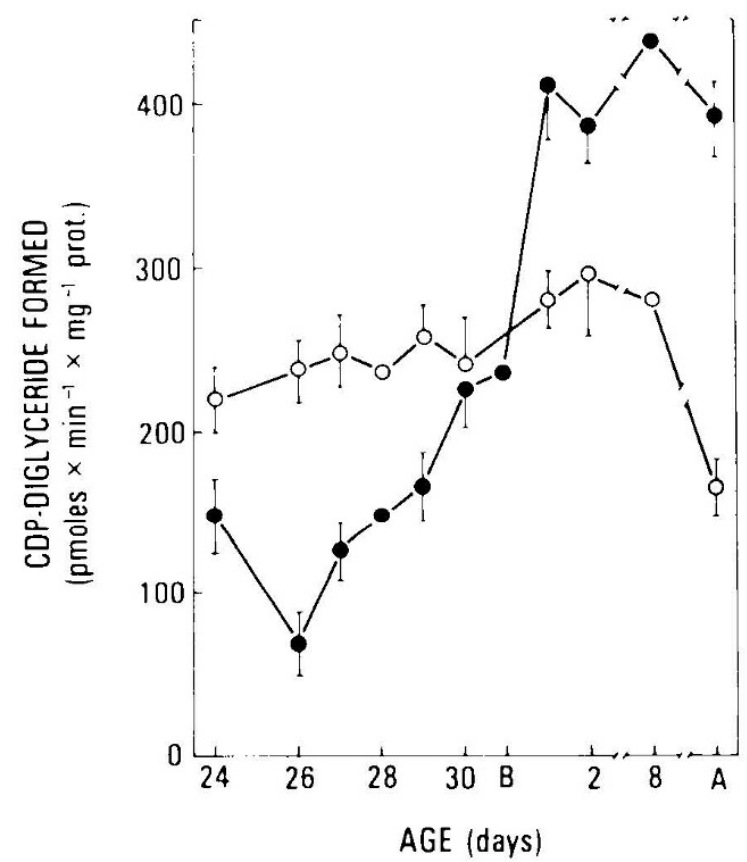

Fig. 3. The activities of phosphatidate cytidyltransferase in mitochondria $(O)$ and microsomes $(\Theta)$ during perinatal development. The results are the means \pm S.E. of four to seven assays run in duplicate. Whenever two to three assays were performed, only means are shown. Phosphatidic acid and Cutscum were added to the reaction mixture. For details, see "Materials and Methods." $B$, birth; $A$, adult. 
Table 6. Apparent $K_{m}$ 's for enzyme activities involved in the synthesis of $P G$ and $P I^{1}$

\begin{tabular}{|c|c|c|c|c|}
\hline \multirow[b]{2}{*}{ Enzyme } & \multirow[b]{2}{*}{ Substrate } & \multirow[b]{2}{*}{ Age } & \multicolumn{2}{|c|}{$\mathrm{K}_{\mathrm{m},}(\mathrm{mM})$} \\
\hline & & & Microsomes & Mitochondria \\
\hline \multirow[t]{3}{*}{$\begin{array}{l}\text { Phosphatidate } \\
\text { cytidyltransferase }\end{array}$} & $\begin{array}{l}\text { Cytidine } \\
\text { triphosphate }\end{array}$ & $\mathrm{Fe} 27 \mathrm{D}^{2}$ & 0.85 & n.m. \\
\hline & & $\mathrm{Fe} 31 \mathrm{D}$ & 1.13 & n.m. \\
\hline & & Adult & 1.09 & n.m. \\
\hline \multirow{6}{*}{$\begin{array}{l}\text { Glycerophosphate } \\
\text { phosphatidyltransferase }\end{array}$} & Sn-Glycerol- & Fe $24-27 \mathrm{D}$ & 0.02 & 0.02 \\
\hline & $3-P$ & NB $1 D^{4}$ & 0.03 & 0.03 \\
\hline & & Adult & 0.03 & 0.03 \\
\hline & CDP-digly- & & & \\
\hline & $\begin{array}{l}\text { ceride (egg } \\
\text { lecithin) }\end{array}$ & $\mathrm{Fe} 27 \mathrm{D}$ & 0.07 & 0.10 \\
\hline & & Adult & 0.07 & 0.08 \\
\hline CDP-diglyceride & Myo-Inositol & Fe 26-29 D & 0.09 & n.m. \\
\hline Inositol & & Adult & 0.07 & n.m. \\
\hline Transferase & CDP-digly- & $\mathrm{Fe} 29 \mathrm{D}$ & 0.09 & n.m. \\
\hline & $\begin{array}{l}\text { ceride (egg } \\
\text { lecithin) })^{5}\end{array}$ & Adult & 0.10 & n.m. \\
\hline
\end{tabular}

${ }^{1}$ The enzyme activities were assayed in the presence of increasing concentrations of the substrate (from $1 \mu \mathrm{M}$ to $6 \mathrm{mM}$. seven to 12 different concentrations), and $\mathrm{K}_{\mathrm{m}}$ was calculated using Lineweaver-Burk plot. Substrate inhibition was not detected.

${ }^{2}$ Twenty-seven-day-old fetus.

${ }^{3}$ n.m., not measured.

4 One-day-old newborn.

${ }^{5}$ Incubation medium containing CDP-diglyceride was prepared by sonication using a micro tip (Cell disruptor; Heat Systems, Ultrasonics, Inc., NY).

photransferase gradually fell between the 24 th fetal day and term. After birth, there was a transient increase in the activity. On the other hand, the mitochondrial activity revealed a gradual fall throughout development. In the incubation conditions used, no diphosphatidylglycerol formation was detected.

In contrast to mitochondria, microsomal glycerophosphate phosphatidyltransferase was low in the 26- to 27-day-old fetus, but increased almost 3-fold during the last fetal days and the first neonatal day. Besides that increase, only small changes in the activity were detected. Even in the adult, the microsomal activity was 62 to $43 \%$ of the corresponding mitochondrial activity. As shown in Figure 5, dicaproyl CDP-diglyceride gave the highest reaction rate. However, in mitochondria CDP-diglyceride derived from egg lecithin was almost as effective as the dicaproyl derivative.

Table 6 shows $\mathrm{K}_{\mathrm{m}}$ 's for $s n$-glycerol-3-P and CDP-diglyceride as measured in different age groups. Again, only small changes among the different age groups were seen.

Table 7 illustrates the distribution of the label between phosphatidylglycerolphosphate and PG. In the present conditions, most of the label was associated with PG. However, the PG: phosphatidylglycerolphosphate ratio of the label increased during the last fetal days and decreased in the newborn. No label was associated with either diphosphatidylglycerol or bis(monoacylglycerol)phosphate. The demonstration of diphosphatidylglycerol synthesis in mitochondria requires a longer incubation time (19). bis(Monoacylglycerol)phosphate formation was only found in lysosomes (data not shown).

Phosphatidylglycerophosphatase. Table 8 shows the activities in microsomal and lamellar body fractions. In microsomes phosphatidylglycerophosphatase increased 3.5 -fold between the $24 \mathrm{th}$ and 26 th and 30 th and 31 st fetal days. After birth, the activity fell to $70 \%$ of its highest fetal value. The corresponding changes in lamellar bodies were smaller. Furthermore, the specific activity of phosphatidylglycerophosphatase associated with lamellar body fraction was $44 \%$ or less of the corresponding microsomal activity. Comparison between microsomal glycerophosphate phosphatidyltransferase and phosphatidylglycerophosphatase activities revealed that the latter exceed the former by at least 90 -fold.

\section{DISCUSSION}

In the present communication, we have further characterized the sequential changes that take place in the acidic phospholipids during perinatal development in the rabbit. In the lamellar body fraction and the alveolar lavage, phosphatidylserine, PI, and PG, in that order, each were the prominent acidic phospholipid at the particular stage of development. A fall in one phospholipid was accompanied by an increase in another phospholipid. The same phenomenon was observed among the acidic phospholipids in human amniotic fluid, suggesting similar development and further confirming the continuity between the fetal lung secretions and the amniotic fluid (18).

Earlier study on lipids of the lung and alveolar lavage failed to disclose similar changes in the acidic phospholipids (42). This may be due to differences in the methods of lipid analysis.

\section{MECHANISM OF ACIDIC SURFACTANT PHOSPHOLIPID FORMATION}

The mechanism underlying the successive development and the mutual relationship between surfactant PI and PG is poorly known $(20,28,36)$. In the present communication, we have investigated this problem by studying the apparent rates of $P G$ and PI synthesis in lung slices using glycerol, myo-inositol, and $s n$-glycerol-3-P as precursors. Comparison of the changes in PG and PI contents (Table 3 ) and those in the corresponding incorporation rates (Fig. 2) revealed some similarity. The measured changes could be due to changes either in transport and distribution, in precursor pools, or in activities of enzymes. To evaluate this question, we further studied the development patterns of four enzyme activities involved in the formation of PG and PI in subcellular fractions of the lung. During fetal development, microsomal phosphatidate cytidyltransferase (I) and CDP-diglyceride:inositol transferase (IV) increased in activity parallel to increase in lamellar body PI. At term and after birth, microsomal glycerophosphate phosphatidyltransferase (II) and phosphatidate cytidyltransferase (I) increased. At the same time, PG appeared in surfactant.

Mitochondria and lamellar bodies contain enzymatic activities involved in PG synthesis, too $(4,19,26,41)$. Even though mito- 


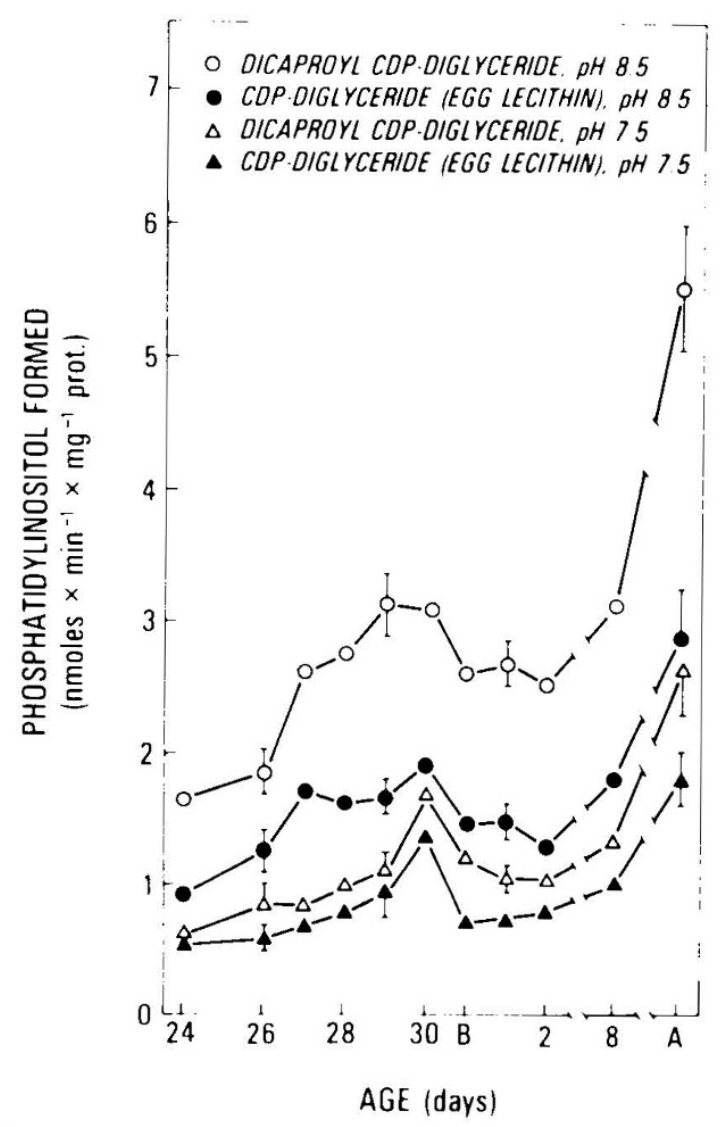

Fig. 4. CDP-diglyceride:inositol transferase activities in microsomes during perinatal development. Each assay was run in four different conditions as shown in the Figure. For further details, see "Materials and Methods" and Figure 3.

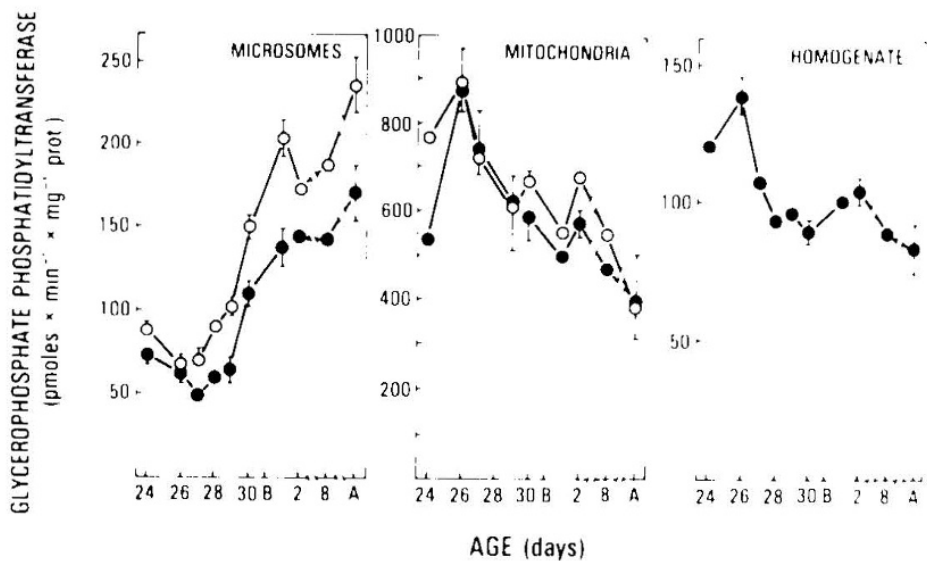

Fig. 5. Glycerophosphate phosphatidyltransferase activities in microsomes, mitochondria, and in cell-free homogenate during perinatal development. Dicaproyl CDP-diglyceride $(O)$ or CDP-diglyceride derived from egg lecithin (O), were used as precursors. For further details, see "Materials and Methods" and Figure 3.

chondrial glycerophosphate phosphatidyltransferase exceed that in microsomes by at least 1.6-fold, the mitochondrial activity showed no correlation to the amount of surfactant PG, but fell rather than increased during development. Furthermore, mitochondria isolated from various tissues possessed appreciable quantities (comparable to those in the lung) of phosphatidate cytidyltransferase, glycerophosphate phosphatidyltransferase, and phosphatidylglycerophosphatase (46). These enzymes apparently participate in the synthesis of cardiolipin (diphosphatidylglycerol), a characteristic mitochondrial structural component. Cardiolipin synthesis expectedly reflects the rate of biosynthesis of mitochondrial membranes. Therefore, the activities that we found in mitochondria may only reflect an autonomous biosynthesis characteristic to these organelles.

Lamellar bodies isolated by the present method possessed appreciable quantities of phosphatidylglycerophosphatase activity, whereas the other three enzyme activities measured were low throughout and probably solely reflected microsomal contamination. However, even phosphatidylglycerophosphatase in lamellar bodies had a lower specific activity than that in the microsomal fraction. In addition, the estimated protein content of lamellar bodies $(0.04 \%$ of whole-lung protein) is much lower than that of microsomes $(21 \%$ of whole-lung protein) or mitochondria ( $18 \%$ of whole-lung protein) (19). Therefore, the contribution of lamellar body associated phosphatidylglycerophosphatase to the total activity is small, indeed. Furthermore, phosphatidylglycerophatase never seemed to be rate limiting because it always exceeded the activity of glycerophosphate phosphatidyltransferase by at least 90-fold, and phosphatidylglycerophosphate was not detected in measurable quantities in the lung. Thus the role of lamellar body associated activity remains open. According to recent evidence. lamellar body associated phosphatase(s) exhibit a low substrate specificity $(4,11,26)$. Its role may indeed prove to be other than biosynthesis of surfactant phospholipids. In addition, the possibility that some of the enzyme activities found in the lamellar body fraction represents lysosomal contamination has not been rigorously disproven.

Kinetic studies using radioactive lipid precursors in vivo support in view of the present study that PG and PI synthesis take place in microsomal membranes and that these phospholipids are transported from there to lamellar bodies and eventually released to alveolar spaces $(1,8,25)$. According to the proposed mechanism for surfactant PG and PI synthesis, microsomal CDP-diglyceride: inositol transferase and glycerophosphate phosphatidyltransferase activities compete for their common substrate, CDP-diglyceride. Even though the specific activities of these microsomal enzymes change parallel to surfactant composition during the perinatal period, CDP-diglyceride:inositol transferase as compared to glycerophosphate phosphatidyltransferase was inappropriately high to totally account for the dramatic increase in surfactant PG. The finding that microsomal glycerophosphate phosphatidyltransferase had higher affinity for CDP-diglyceride than CDP-diglyceride: inositol transferase (Table 6) can partially explain this discrepancy

Table 7. The activity of glycerophosphate phosphatidyltransferase in microsomal fraction and in mitochondria from developing rabbits ${ }^{1}$

\begin{tabular}{llcc}
\hline & & \multicolumn{2}{c}{ PG/PGP } \\
\cline { 3 - 3 } \multicolumn{1}{c}{ Age } & $N^{2}$ & $\begin{array}{c}\text { Microsomal } \\
\text { fraction }\end{array}$ & Mitochondria \\
\hline Fetus & & 1.8 & 3.4 \\
$24-26$ days & 2 & 2.4 & 4.2 \\
$28-29$ days & 3 & 3.0 & 6.3 \\
30 days & 3 & & 4.7 \\
Newborn & & 1.2 & 2.8 \\
$\quad$ 1-3 days & 3 & 1.6 & \\
Adult female & 2 & & \\
\hline
\end{tabular}

'Distribution of the radioactive label between PG and phosphatidylglycerol phosphate. The assay of glycerophosphate phosphatidyltransferase was performed as described in "Materials and Methods." After $10 \mathrm{~min}$ of incubation with the radioactive precursor, the lipids were isolated by two-dimensional thin-layer chromatography and assayed for the radioactivity. In the present conditions, no radioactivity was associated with either cardiolipin or bis(monoacylglycerol) phosphate.

${ }^{2} N$, number of assays.

${ }^{3}$ PGP, phosphatidylglycerolphosphate. 
Table 8. The activity of phosphatidylglycerophosphatase in lung microsomal fraction and lamellar bodies from developing rabbits

Phosphatidylglycerolphosphate formed (nmoles $\times \min ^{-1} \times \mathrm{mg}^{-1}$ protein)

\begin{tabular}{lllr}
\multicolumn{1}{c}{ Age } & $N^{1}$ & $\mathrm{Ms}^{2}$ & LB \\
\hline Fetus & & & \\
24-26 days & 2 & 12.1 & 6.6 \\
$28-29$ days & 3 & 15.7 & 13.5 \\
30-31 days & 3 & 42.0 & \\
Newborn & & & 10.9 \\
I-3 days & 2 & 29.3 & 9.5 \\
Adult female & 3 & 21.8 & \\
\hline
\end{tabular}

' $N$, Number of assays.

${ }^{2} \mathrm{Ms}$, microsomal fraction, LB, lamellar bodies.

since intracellular CDP-diglyceride concentrations are characteristically low (45). However, in the adults, there was no correlation between the acidic surfactant phospholipids and the microsomal biosynthetic activities (Fig. 6).

The fact that the ontogeny of acidic surfactant phospholipids cannot solely be explained on the basis of changing enzyme activities, may be owing to some of the following possibilities. The alternative that factors other than biosynthesis rate, such as changes in intracellular transport or affinity of phospholipid binding protein regulate surfactant composition, has no experimental support (29). Increase in lung PG was preferentially, if not only due to induction of surfactant PG, whereas lung fractions, other than surfactant, contain only small amounts of this phospholipid (19). Surfactant composition may also be dependent on catabolism rates of individual components. Again, the evidence of Jobe and Gluck (24) fails to support this alternative. It is further possible that microsomal CDP-diglyceride:inositol transferase mostly originates from other than alveolar type II cells. Moreover, the distribution of the enzymes between various lung cells may change during development. These possibilities need to be evaluated by comparative studies using subcellular fractions derived from isolated type II alveolar cells. Finally, changes in substrate concentration may control the biosynthetic rates.

As studied in various species, myo-inositol concentration in the fetus is high. In the rat serum, it falls sharply at birth (6), whereas in the human, the corresponding change is more gradual (31). In contrast to myo-inositol, serum glycerol increases at birth (38). These changes could contribute to the characteristic alterations in the acidic surfactant phospholipids. However, serum levels may not necessarily reflect the levels at the biosynthetic site. Indeed, discrepancies between serum and tissue levels of myo-inositol have been found (37). Furthermore, even if serum glycerol is utilized effectively for surfactant biosynthesis (34), factors regulating intracellular $s n$-glycerol-3-P concentration are complex and may not corelate with serum glycerol levels. The possibility that availability of substrates, particularly myo-inositol, plays an additional role in the ontogeny of surfactant phospholipids remains an attractive alternative that needs to be studied further.

\section{ROLE OF ACIDIC SURFACTANT PHOSPHOLIPIDS}

Disaturated PC is synthesized by a series of enzymatic reactions that characteristically change during development (for review, see Ref. 47). According to Stern et al. (46), phosphocholine cytidyltransferase, catalyzing the formation of CDP-choline, may be rate limiting in de novo formation of PC in the lung. As measured in the lung supernatant, the activity increased at birth. This was due to enzyme activation rather than synthesis of new enzyme protein (13). Of the activators tested, PG was the most effective, followed by PI and phosphatidylserine. However, the enzyme activity obtained from adults was little affected by addition of phospholipids, possibly because the acidic phospholipids already were present in optimal concentration. This finding illustrates a mechanism controlling biosynthesis of various surfactant phospholipids.

It is tempting to speculate that during the late fetal period the successive increase in phosphatidylserine, PI and PG activates phosphocholine cytidyltransferase and thereby increases surfactant PC synthesis.

The crucial role of disaturated PC in achieving low surface tension on peripheral airway lining is accepted widely (17). However, it has become increasingly evident that disaturated lecithin alone cannot perform all surfactant functions; in particular, it does not spread effectively on the alveolar surface. We have proposed that physicochemical properties of surfactant are modified by changes in the composition of acidic phospholipids $(18,21)$. To further test this hypothesis, Ikegami et al. (23) used mixtures of dipalmitoyl PC and various acidic phospholipids to restore lung pressure-volume characteristics in surfactant depleted lungs. Combination of PG with disaturated PC was the most effective, followed by PI + disaturated PC, and phosphatidylserine + disaturated PC. In addition, Bangham et al. (3) found evidence, that a mixture of PG and dipalmitoyl PC improves spreading of disaturated species on surface and allows dipalmitoyl PC enriched monolayer to be repeatedly compressed to a minimum surface tension of about zero dynes $\times \mathrm{cm}^{-1}$ (3). These studies need to be extended to involve other surfactant components, too. Furthermore, the potential role of the acidic phospholipids in modifying the secretion of surfactant from epithelial cells to alveolar spaces entirely remains to be studied.

The ontogeny of surfactant is a complex process involving development of functions such as biosynthesis, intracellular transport, release from the intracellular storage, and spreading on alveolar surface at birth. Accordingly, there is no single specific etiology of surfactant deficiency in RDS because the cause varies during development. The stepwise appearance of acidic surfactant phospholipids as shown in the present study, further implies the complexity of regulation. Measurement of acidic phospholipids, not just disaturated PC, may better differentiate between the actions of hormones that control lung development. Monitoring of the lung profile ( $\mathrm{L} / \mathrm{S}$ ratio, percentage of disaturated $\mathrm{PC}, \mathrm{PG}$,
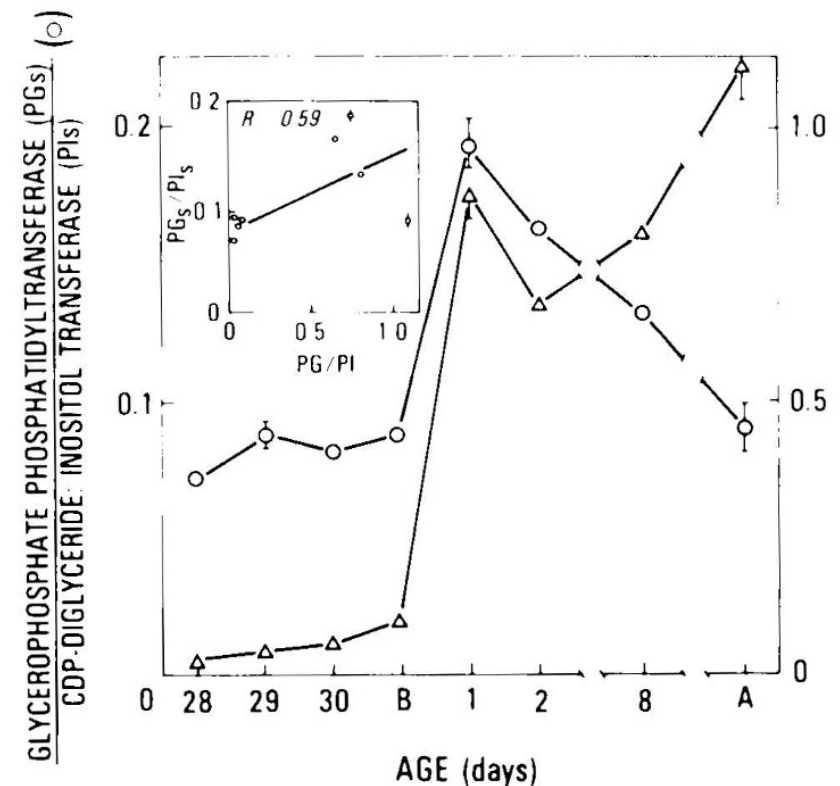

Fig. 6. Correlation between the ratio of microsomal glycerophosphate phosphatidyltransferase to CDP-diglyceride:inositol transferase (nmoles $\times \min { }^{\prime} \times \mathrm{mg}$ ' protein:nmoles $\times \mathrm{min}^{-1} \times \mathrm{mg}^{-1}$ protein) and the ratio of phosphatidylglycerol to phosphatidylinositol in lamellar bodies (\% of lipid$\mathrm{P}: \%$ of lipid-P). The enzyme activities were assayed in the presence of dicaproyl CDP-diglyceride ( $\mathrm{pH} 7.4$ and $\mathrm{pH} 7.5$, respectively). $B$, birth; $A$, adult. 
and PI) in the amniotic fluid enables even more exact evaluation of the degree of functional development than the $\mathrm{L} / \mathrm{S}$ ratio alone (30). Hopefully, a better understanding of both the ontogeny of surfactant and the risks involved in medical interference with lung maturation enables further reduction of the incidence of RDS in those cases where prevention of prematurity fails.

\section{REFERENCES AND NOTES}

1. Askin, F. B., and Kuhn, C.: The cellular origin of pulmonary surfactant. Lab. Invest.. 25: 260 (1971).

2. Avery. M. E.. and Mead. J.: Surface properties in relation to atelectasis and hyaline disease. Am. J. Dis. Child., 97: 517 (1959).

3. Bangham, A. D., Morley, C. J., and Phillips, M. C.: The physical properties of an effective lung surfactant. Biochim. Biophys. Acta, 573: 552 (1979).

4. Benson, B. J., and Clements, J. A.: Characterization of a pulmonary surfactantassociated acid phosphatase. Fed. Proc.. 37: 1493 (1978)

5. Bligh, E. G., and Dyer. W. J.: A rapid method of total lipid extraction and purification. Can. J. Biochem. Physiol., 37: 911 (1959).

6. Burton, L. E.. and Wells, W. W.: Studies on the development pattern of the enzymes converting glucose-6-phosphate to myo-inositol in the rat. Dev. Biol., 37: 35 (1974).

7. Chang, Y. Y., and Kennedy, E. P: Biosynthesis of phosphatidyl glycerophosphate in Escherichia coli. J. Lipid Res., 8: 447 (1967).

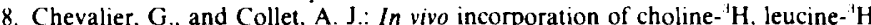
and galactose- $\mathrm{H}$ in alveolar type II pneumocytes in relation to surfactant synthesis. Anat. Rec., 174: 289 (1972).

9. Dawson. R. M. C.: Analysis of phosphatides and glycolipids by chromatography of their partial hydrolysis or alcoholysis products. In: G. V. Marinetti: Lipid Chromatographic Analysis. pp. 168-171 (Marcel Dekker Inc.. New York. 1967).

10. De Haas, G. H.. Benson. P. P. M.. and Van Deenen, L. L. M.: Studies on cardiolipin and synthetic diphosphatidyl glycerol. Biochim. Biophys. Acta, //6. 114 (1966).

11. DiAugustine, R. P.: Lung concentric laminar organelle. Hydrolase activity and compositional analysis. J. Biol. Chem., 249: 584 (1974).

12. Eichberg. J., and Hauser, G.: A rapid biosynthetic method for the preparation of radioactive phosphatidyl-CMP (CDP-diacylglycerol) of high specific activity J. Lipid Res., 19: 778 (1978).

13. Feldman, D. A.. Kovac, C. R., Dranginis, P. L., and Weinhold, P. A.: The role of phosphatidylglycerol in the activation of CTP: phosphocholine cytidyltrans ferase from rat lung. J. Biol. Chem., 253: 4980) (1978).

14. Gluck, L., Kulovich, M. V., Borer, R. C., Jr., Brenner, P. H., Anderson. G. G. and Spellacy, W. N.: Diagnosis of the respiratory distress syndrome by amniocentesis. Am. J. Obstet. Gynecol. 109: 440 (1971).

15. Gluck, L., Kulovich, M. V., Borer, R. C.. and Keidel, W. N.: The interpretation and significance of the lecithin/sphingomyelin ratio in amniotic fluid. Am. J. Obstet. Gynecol., 120: 148 (1974).

16. Gluck. L.. Scribney, M., and Kulovich, M. V.: The biochemical development of surface activity in mammalian lung II. The biosynthesis of phospholipids in the lung of the developing rabbit fetus and newborn. Pediatr. Res., l: 247 (1967).

17. Goerke, J.: Lung surfactant. Biochim. Biophys. Acta.. 344: 241 (1974).

18. Hallman, M., Feldman, B. H., Kirkpatrick. E., and Gluck, L.: Absence of phosphatidylglycerol in respiratory distress syndrome in the newborn. Pediatr. Res., 11: 714 (1977)

19. Hallman, M.. and Gluck. L.: Phosphatidylglycerol in lung surfactant II. Subcellular distribution and mechanism of biosynthesis in vitro. Biochim. Biophys. Acta. 409: 172 (1975).

20. Hallman. M., and Gluck. L.: The biosynthesis of phosphatidylglycerol in the lung of the developing rabbit. Fed. Proc., 34: 274 (1975).

21. Hallman, M., and Gluck, L.: Phosphatidylglycerol in lung surfactant III. Possible modifier of surfactant function. J. Lipid Res., 17: 257 (1976).

22. Hallman. M., Kulovich. M. V., Kirkpatrick, E., Sugarman, R. G., and Gluck, L Phosphatidylinositol and phosphatidylglycerol in amniotic fluid: indices of lung maturity. Am. J. Obstet. Gynecol.. 125: 613 (1976).

23. Ikegami. M.. Silverman. J., and Adams, F. H.: Restoration of lung pressure volume characteristics with various phospholipids. Pediatr. Res., 13: 777 (1979)
24. Jobe, A.. and Gluck, L.: The labeling of lung phosphatidylcholine in premature rabbits. Pediatr. Res., 134: 635 (1979).

25. Jobe, A. Kirkpatrick, E., and Gluck, L.: Labeling of phospholipids in the surfactant and subcellular fractions of rabbit lung. J. Biol. Chem., 253: 3810 (1978).

26. Johnston, J. H., Reynolds, G., Wylie, M. B., and MacDonald, P. C.: The phosphohydrolase activity in lamellar bodies and its relationship to phosphatidylglycerol and lung surfactant formation. Biochim. Biophys. Acta.. 531: 65 (1978).

27. Kankare. P., and Suovameni, O.: A simple method for determination of phosphate from thin-layer chromatographic plates. J. Chromatogr., 62: 485 (1971)

28. Katyal, S. L.. Estes. L. W., and Lombardi. B.: Method for the isolation of surfactant from homogenates and lavages of lung of adult, newborn, and fetal rats. Lab. Invest., 365: 85 (1977).

29. King, R. J., Ruch, J., Gikas, E. G., Platzker, A. C. G., and Creasy, R. K Appearance of apoproteins of pulmonary surfactant in human amniotic fluid. J. Appl. Physiol., 39: 735 (1975).

30. Kulovich, M. V., Hallman, M., and Gluck, L.: Lung profile I. Normal pregnancy. Am. J. Obstet. Gynecol., 134: 57 (1979).

31. Lewin. L. M.. Melmed, S.. Passwell, J. H., Yannai, Y.. Brish, M.. Orda, S.

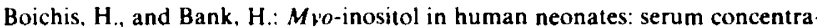
tions and renal handling. Pediatr. Res., 12: 3 (1978).

32. Lowry, O. H., Rosebrough. N. J., Farr, A. L., and Randall, R. J.: Protein measurements with the Folin phenol reagent. J. Biol. Chem., 193: 265 (1951).

33. Mason. R. J., Nellenbogen, J., and Clements. J. A.: Isolation of disaturated phosphatidylcholine with osmium tetroxide. J. Lipid Res., 17: 281 (1976).

34. Mims, L. C., Mazzuckelli, F., and Kotas, R. V.: The significance of circulating glycerol as a precursor of pulmonary phosphatidylcholine in the developing mammalian lung. Pediatr. Res., 9: 165 (1975).

35. Obladen. M.: Factors influencing surfactant composition in the newborn infant. Eur. J. Pediatr., /28: 129 (1978)

36. Okano, G.. and Akino. T.: Variations in the molecular species of lung phosphatidylglycerol. Lipids, 14: 541 (1979)

37. Palmano. K. P., Whiting. P. H., and Hawthorne, J. N.: Free and lipid myoinositol in tissues from rats with acute and less severe streptozotocin induced diabetes. Biochem. J., 167: 229 (1977).

38. Persson, B., and Gentz. J.: The pattern of blood lipids, glycerol and ketone bodies during the neonatal period, infancy and childhood. Acta Paediatr. Scand.. 55: 353 (1966).

39. Rapport, M. M., and Alonzo, N.: Photometric determination of fatty acid ester groups in phospholipids. J. Biol. Chem., 217: 193 (1955).

40. Renkonen. O.: Determination of glycerol in phosphatides. Biochim. Biophys. Acta. 56: 367 (1962).

41. Rooney, S. A., Page-Roberts, B. A., and Motoyama, E. K.: Role of lamellar inclusions in surfactant production: studies on phospholipid composition and biosynthesis in rat and rabbit lung subcellular fractions. J. Lipid Res., 16: 418 (1975).

42. Rooney, S. A., Wai Lee, T. S., Gobran, L.. and Motoyama, E. K.: Phospholipid content, composition and biosynthesis during fetal lung development in the rabbit. Biochim. Biophys. Acta, 431: 447 (1976).

43. Sottocasa, G. L., Kuylenstierna. B., Ernster, L., and Bergstrand, A.: An electrontransport system associated with the outer membrane of liver mitochondria: a biochemical and morphological study. J. Cell Biol.. 32: 415 (1967).

44. Stern, W., Kovac, C., and Weinhold. P. A.: Activity and properties of CTP: cholinephosphate cytidyltransferase in adult and fetal rat lung. Biochim. Biophys. Acta, 441: 280 (1976).

45. Thompson, W.. and MacDonald G.: Isolation and characterization of cytidine diphosphate diglyceride from beef liver. J. Biol. Chem., 250: 6779 (1975).

46. Van Den Bosch. H.: phosphoglyceride metabolism. Am. Rev. Biochem.. 43: 243 (1974).

47. Van Golde. L. M. G.: Metabolism of phospholipids in the lung. Am. Rev. Respir. Dis., 114: 977 (1976).

48. Webb. R. A. and Mettrick. D. F. Quantitative liquid scintillation radioassay of phospholipids from thin-layer chromatograms. J. Chromatogr.. 67: 75 (1972).

49. Requests for reprints should be addressed to: Mikko Hallman. M.D., Department of Pediatrics, C/019, University of California, San Diego, La Jolla, California 92093 (USA).

50. This research was supported by National Institutes of Health grants HDI0622 and SCOR HL23584.

51. Received for publication November 5, 1979

52. Accepted for publication February 5, 1980. 